\title{
Study on the Influencing Factors of Technical Innovation Performance in Vocational College
}

\author{
Z.X. YAN \& Y.J. BIAN \\ Business School of Hohai Uinversity, Nanjing, Jiangsu, China
}

\begin{abstract}
Understanding the internal and external factors of technical innovation is crucial to maximize the benefits of innovation in vocational college. Taking regional innovation system perspective, this study focuses on the key factors of technical innovation performance in vocational college. Based on innovation system theory, we first present six influencing factors. And then through factor analysis, three key influencing factors are obtained such as innovation resource, innovation process, and innovation environment. Finally, this paper analyzes the relationship and the influence the three key factors impact on technical innovation performance in vocational college by principal component regression. It is found that all of the three factors have significant positive effect on technical innovation performance and the innovation resource has the greatest impact.
\end{abstract}

KEYWORD: Vocational college; Technical innovation; Influencing factor; Regression analysis

\section{INTRODUCTION}

Vocational college as an important part of regional innovation system, provides a variety of technical services, and effectively supports the regional industrial transformation and upgrading. Scientific and technical work in vocational college is mainly applied research and technical innovation in order to solve the technical problems of industrial development and meet the demand of technical transformation.

Current research on technical innovation of vocational college is less, mostly for university. But there are some features as lack of talents, less scientific ability, lack of resources in vocational college. This paper from the perspective of regional innovation system, empirical analyzes the key factors affecting technical innovation performance in vocational college.

\section{RESEARCH HYPOTHESIS}

Regional innovation system is a complex system promoting regional innovation activities which is consisting of multiple factors and taking enterprise as main innovator (Cooke et al. 1998, 2004). The vocational college has distinctive regional characteristics. In essence, technical innovation in vocational college is a creative process in a certain environment, which takes the successful transformation as the target (Bernstein \& Singh 2006), bases on R\&D personnel, by using the soft and hard resources to technology development (Doloreux 2002).

So the innovation performance in vocational college is the level of transforming innovation achievements into productivity forces, which is influenced by all kinds of innovation resources (Wang \& Huang 2007, Bonaccorsi \& Daraio 2003), industrial development and innovation policy, etc. Hence, this paper studies the influence from 6 aspects.

\section{$2.1 R \& D$ talents}

Carrying out technical innovation needs enough research personnel and their ability should meet the need of R\&D projects (Parks \& Grileches 1980, Romer 1990). Currently, technical innovation project is not the one which can be completed by one person like before, but need to set up R\&D team, each team member has specific duties division and study in cooperation. So we make the following assumption:

H1: The more reasonable talents' allocation, the more improvement of technical innovation performance in vocational college. 


\section{$2.2 R \& D$ funds}

$\mathrm{R} \& \mathrm{D}$ funds need to be invested in the construction of infrastructure (Romer 1990), such as innovation platform, public technical platform, etc. And they also should be invested for specific R\&D projects' need, including the direct costs (Edquist \& Hommen 1999) such as cost of equipment, testing cost, buying experimental materials, allowance for personnel, general operational expenses, etc. and indirect costs such as cooperation fees, management fees, and onthe-spot funds, etc. So we make the following assumption:

$\mathrm{H} 2$ : Abundant funds for technical innovation can effectively improve the performance of technical innovation in vocational college.

\section{$2.3 R \& D$ process}

The process of $R \& D$ project has high risk of uncertainty, the level of technology, project management ability and all kinds of unpredictable factors can make the project failure (Doloreux 2002). R\&D belongs to exploratory work inherently, such as team's knowledge, applicability of R\&D method, and the precision of project management all can affect the performance of R\&D (Faber \& Hesen 2004). The emergence of new problems in process which temporarily unable to be solved, make the research direction and achievements deviated from original research target; the difficulty of R\&D goal maybe be underestimated which lead the development schedule lagged and the quality of outcome fail to meet the target requirements etc. We make the following assumption:

H3: Reducing the risk of $R \& D$ process is beneficial to improve the chances of technical innovation

\subsection{Industrial and innovation policy}

Because $\mathrm{R} \& \mathrm{D}$ in vocational college is closely contacting with the market, the government's policy can support or hinder the innovation (Edquist \& Hommen 1999), such as patent grant policy, cooperation incentive policy, $R \& D$ fund management system, tax exemption for technical services have direct impact on technical innovation in vocational college. The policy of industry development which vocational college relies on and service also have indirect effect on technical innovation. The industries which government support will have relatively strong technical demand, and it is easy to carry out industry-college-research cooperation, which is more conducive to produce outstanding achievements. The stability and continuity of policy also have impact on technical innovation. We make the following assumption:
H4: Good industrial and innovation policy is effectively conducive to enhance technical innovation performance.

\subsection{Industrial development}

The relationship between vocational college and industry which vocational college bases on and services is mutualistic symbiosis. When the industry is in high speed development stage, there will grow very strong demand for innovation and it becomes a huge market for innovation achievements (Doloreux 2002, Furman et al. 2002). This can effectively boost technical innovation in vocational college for keeping up with the pace of industrial development. If the industry is in stagnant or shrinking stage, the application market of achievement will be corresponding atrophic, and the transformation of technical achievements will be difficult. We make the following assumption:

H5: The healthy and orderly development of industry which vocational college bases on is conducive to enhance the performance of technoical innovation.

\subsection{Transformation}

Vocational college should have marketing idea, service concept, and carry out market-oriented technical research and promotion which makes the demand side knows and chooses the achievements (Pakes \& Grileches 1980, Furman et al. 2002). Successful transformation of innovation project needs to consider the actual situation of enterprise, such as production environment, equipment, capital investment, etc. Accordingly, we make the following assumption:

H6: The more effective transformation of technical achievement, the more can enhance the performance of technical innovation.

\section{QUESTIONNAIRE INVESTIGATION}

According to the six assumptions above, we design a questionnaire which is consisted of basic information and measurement of impact of assumptions. The basic information includes identity of people surveyed, information of college and situation of technical innovation. The measurement uses Likert scale which scores from 1 to 5 . In order to ensure the reliability and validity of questionnaire, the investigation is taken into two stages as presurvey and formal investigation.

Pre-survey: 60 samples are randomly selected from the sample space for survey, and 52 valid questionnaires are collected. According to the respondents' opinion and reaction, specific 
description of some questiones are revised and perfected, and two inappropriate items are removed.

Formal investigation: After revising questionnaire, by the general survey way, we sent out 1000 formal questionnaires to nationwide vocational colleges. A total of 263 questionnaires are recovered, the rate of recycling is $28 \%, 254$ valid questionnaires among them, and the effective questionnaire percentage is $95 \%$.

\section{RESEARCH PROCESS AND RESULTS}

\subsection{Reliability and validity of the scale}

This paper uses the Cronbach's $\alpha$ to judge the reliability. By reliability testing of each research variable, all of the Cronbach's $\alpha$ of variables are more than 0.6; with the exception of the industrial risk is 0.526 , less than 0.6. The Cronbach's $\alpha$ of whole scale is 0.824 , as shown in Table 1 . This shows that the questionnaire has higher reliability.

The construct validity of scale can be analyzed by exploratory factor analysis. After calculation, the cumulative explained variance of 6 factors in the scale reach $70.32 \%$, this shows that the questionnaire has higher validity.

Through testing of reliability and validity, we can consider the questionnaire is scientific and reasonable in this study, the scale can be used to measure the cognition about people surveyed understands the influencing factors of technical innovation in vocational college.

Table 1 . Reliability test of scale data by using Cronbach's $\alpha$.

\begin{tabular}{|l|l|}
\hline Factor & Cronbach's $\alpha$ \\
\hline R\&D talents & 0.821 \\
\hline R\&D funds & 0.634 \\
\hline R\&D process & 0.748 \\
\hline Policy & 0.748 \\
\hline Industrial development & 0.526 \\
\hline Transformation & 0.768 \\
\hline Total & 0.824 \\
\hline
\end{tabular}

\subsection{Key factors}

This article first uses KMO and Bartlett's test to determine whether the scale is suitable for factor analysis. Then, by testing MSA value of individual item, we determine which item is not suitable for factor analysis.

\subsubsection{Suitable testing for factor analysis}

As shown in Table 2, the correlation matrix which represents statistical population has common factors and it is suitable for factor analysis. All of the MSA values are greater than 0.5 which can be got from the Anti-image Matrices, indicating that the items are all suitable for factor analysis.
Table 2. Kaiser-Meyer-Olkin and Bartlett's test for suitable.

\begin{tabular}{|l|l|l|}
\hline $\begin{array}{l}\text { Kaiser-Meyer- } \\
\text { Olkin }\end{array}$ & Measure of Sampling Adequacy & 0.784 \\
\hline \multirow{2}{*}{$\begin{array}{l}\text { Bartlett's Test of } \\
\text { Sphericity }\end{array}$} & Approx. Chi-Square & 1381.249 \\
\cline { 2 - 3 } & Df & 153 \\
\cline { 2 - 3 } & Sig. & 0 \\
\hline
\end{tabular}

\subsubsection{Extracting key factors}

By using principal component analysis to extract the factor which eigenvalue is greater than 1 , we can extract 3 common factors, and theire accumulated variance contribution is $78.536 \%$. We use Varimax method for orthogonal rotation by Kaise normalization, the rotated component matrix is shown in Table 3.

The common factor 1 can explain two original variables: $R \& D$ talents, $R \& D$ funds. The performance of $R \& D$ team building is closely related to the part of innovation funds which are invested in team building and training, innovation funds and research facilities impact talents' ability to function. So this common factor can be named as factor of innovation resource.

The common factor 2 can explain R\&D process, transformation. The effect of transformation and application should be considered in the process of R\&D. Transformation is the value of innovation. These two variables are both reflect the existing problems and condition in $R \& D$ process and transformation. So it can be named as factor of innovation process.

The common factor 3 can explain industrial development and innovation policy. The industrial development trend, policy of industrial development and innovation are external environment of innovation in vocational college. These two variables reflect the effect of external environment of innovator on promoting the transformation of $\mathrm{R} \& \mathrm{D}$ achievements into real productive forces, so it can be named as factor of innovation environment.

Table 3. Rotated component matrix by Kaise normalization.

\begin{tabular}{|l|l|l|l|}
\hline \multirow{2}{*}{ Factor } & \multicolumn{4}{ll}{ Component } \\
\cline { 2 - 4 } & 1 & 2 & 3 \\
\hline R\&D talents & 0.905 & 0.103 & 0.015 \\
\hline R\&D funds & 0.887 & 0.09 & 0.139 \\
\hline R\&D process & -0.008 & 0.909 & 0.072 \\
\hline Transformation & 0.224 & 0.867 & 0.091 \\
\hline Industrial development & 0.005 & -0.004 & 0.867 \\
\hline Policy & 0.141 & 0.163 & 0.791 \\
\hline
\end{tabular}

\subsubsection{Testing significance of key factors}

This paper uses principal component regression for test. By using principal component analysis to extract the factor which eigenvalue is greater than 1 from talent factor and research funds factor, one common factor can be gotten, which can explain $82.368 \%$ of the total variance. The weighted coefficients of two 
original variables corresponding to the principal component are $0.908,0.908$. This reflects the two orginal variables even contribute to the principal component, and they can be replaced by one principal component which is named as factor of innovation resource.

In the same way, common factor 2 can be gotten from $R \& D$ process and transformation named as factor of innovation process. Common factor 3 can be gotten from industrial development factor and innovation policy factor named as factor of innovation environment.

\subsection{Stepwise multiple regression analysis}

We use stepwise multiple regression method to analyse the relationships by taking the innovation performance as dependent variable, innovation resource, innovation process, innovation environment as independent variables. All of the regression coefficients of 3 factors reach significant level, which have significant predictive effect on innovation performance. The effects are positive and results of regression model also reach significant level.

In model 1, taking innovation resource as independent variable into the regression, it accounts for $40 \%$.

In model 2, taking innovation resources and innovation process as independent variables into the regression which jointly account for $63.8 \%$, of which innovation process factor accountes for $23.6 \%, \mathrm{~F}$ value added is 128.623 .

In model 3, taking all three factors as independent variables into the regression which jointly account for $74.9 \%$, of which innovation enviorment factor accountes for $11.1 \%, \mathrm{~F}$ value added is 87.112 .

The regression coefficients of 3 independent variables effect on the dependent variable are 0.474 , 0.44 , 0.348, which can be gotten from the standardized regression coefficient Beta value as shown in Table 4.

Table 4. Coefficients and statistics of linear regression model 3.

\begin{tabular}{|c|c|c|c|c|c|c|}
\hline \multirow{2}{*}{ Model 3} & \multirow{2}{*}{ Standardized Beta } & \multirow{2}{*}{$\mathrm{t}$} & \multirow{2}{*}{ Sig. } & \multicolumn{2}{|c|}{ Collinearity Statistics } & \multirow{2}{*}{$F$} \\
\hline & & & & Tolerance & VIF & \\
\hline (Constant) & & 154.8 & 0 & & & \multirow{4}{*}{195.2} \\
\hline Resource & 0.474 & 12.77 & 0 & 0.927 & 1.078 & \\
\hline Process & 0.44 & 11.97 & 0 & 0.945 & 1.059 & \\
\hline Environment & 0.348 & 9.333 & 0 & 0.923 & 1.084 & \\
\hline
\end{tabular}

\section{CONCLUSION}

The effect of innovation resource affecting the performance of technical innovation is the maximum, which shows that the basic resource allocation more reasonable such as talents, funds and innovation platform and so on, output of innovation can be improved, effective transformation of productive forces and performance of technical innovation can be enhanced. The factor of innovation process has great influence on performance of technical innovation, applying meticulous project management on R\&D, application and transformation, strengthening the process capability is the effective way to enhance the performance of technical innovation. In addition, the factor of innovation environment also has some influence on technical innovation performance in vocational college. The innovation policy is more favorable, industrial development is more benign, more can effectively improve enthusiasm and the performance of technical innovation in vocational college.

\section{REFERENCES}

[1] Bonaccorsi, A. \& Daraio, C. 2003. A robust nonparametric approach to the analysis of scientific productivity. Research Evaluation 12(1): 47-69.
[2] Bernstein, B. \& Singh, P.J. 2006. An integrated innovation process model based on practices of Australian biotechnology firms. Technovation 26(5-6): 561-572.

[3] Cooke, P., Uranga, M.G. \& Etxebarria, G. 1998. Regional systems of innovation: an evolutionary perspective. Environment and Planning A 30(9): 1563-1584.

[4] Cooke, P., Heidenreich, M. \& Braczyk, H.J. 2004. Regional Innovation Systems: The role of governance in a globalized world. NewYork: Routledge.

[5] Doloreux, D. 2002. What we should know about regional systems of innovation. Technology in Society 24(3): 243263.

[6] Edquist, C. \& Hommen, L. 1999. Systems of innovation: theory and policy for the demand side. Technology in Society 21(1): 63-79.

[7] Furman, J.L., Porter, M.E. \& Stern, S. 2002. The determinants of national innovative capacity. Research Policy 31(6): 899-933.

[8] Faber, J. \& Hesen, B. 2004. Innovation capabilities of European nations: Cross-national analyses of patents and sales of product innovations. Research Policy 33(2): 193207.

[9] Pakes, A. \& Griliches, Z. 1980. Patents and R\&D at the firm level: a first report. Economics letters 5(4): 377-381.

[10]Romer, P. 1990. Endogenous Technological Change. The Journal of Political Economy 98(5): S71-S102.

[11]Wang, E.C. \& Huang, W.C. 2007. Relative efficiency of R\&D activities: a cross-country study accounting for environmental factors in the DEA approach. Research Policy 36(2): 260-273. 